\title{
Endoscopic Assisted Retrosigmoid Approach for Cerebellopontine Angle Epidermoid Tumor
}

\author{
Katherine Kunigelis ${ }^{1} \quad$ Alexander Yang $^{1} \quad$ A. Samy Youssef ${ }^{1}$ \\ ${ }^{1}$ Department of Neurosurgery, University of Colorado, Aurora, \\ Colorado, United States \\ J Neurol Surg B 2018;79(suppl S5):S413-S414.

\begin{abstract}
Address for correspondence A. Samy Youssef, MD, PhD, Department of Neurosurgery, University of Colorado, 12631 East 17th Avenue, Box C307, Aurora, CO 80045, United States
\end{abstract} \\ (e-mail: samy.youssef@ucdenver.edu).
}

\begin{abstract}
Keywords

- cerebellopontine angle

- retrosigmoid

- endoscopic assisted

- epidermoid tumor

This case is a 20-year-old male, who presented with 1 month of right facial weakness (HB4) and complaints of ipsilateral eye dryness. He was initially treated for Bell's palsy with steroids and antiviral agents, but subsequently developed diplopia with right lateral gaze and underwent an MRI (magnetic resonance imaging). MRI demonstrated a $4.5 \mathrm{~cm}$ irregular lesion in the right cerebellopontine angle consistent with an epidermoid cyst. Because the tumor had grown with the development of the central nervous system, it has extended into different compartments, including the tentorial incisura and pineal region. A predefined surgical corridor created by the tumor facilitated access to the majority of the tumor through a retrosigmoid approach. Angled endoscopes (30-degree up and down) provided further visualization of tumor away from the line of sight of the microscope, thus allowing for gross total resection of the lesion. This video also demonstrates a sharp dissection technique necessary for safe removal of adherent tumor from critical neurovascular structures, including the basilar artery and several cranial nerves. The ipsilateral auditory evoked responses (ABRs) showed slight improvement from baseline toward the end of the case. A gross total resection was achieved, as shown by the MRI. The patient remained at his baseline cranial nerve (CN) V, VII, and VIII deficits during the immediate postoperative period. The link to the video can be found at: https://youtu.be/vCq5juJh8hk.
\end{abstract}

Conflict of Interest

None.

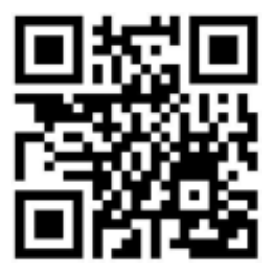

www.thieme.com/skullbasevideos

www.thieme.com/jnlsbvideos received

May 1, 2018

accepted after revision

August 12, 2018

published online

September 25, 2018
DOI https://doi.org/

10.1055/s-0038-1669978.

ISSN 2193-6331.
๑) 2018 Georg Thieme Verlag KG
Stuttgart · New York

License terms

() (i) $\ominus$ (\$) 
S414 Endoscopic Retrosigmoid-Epidermoid Tumor Kunigelis et al.

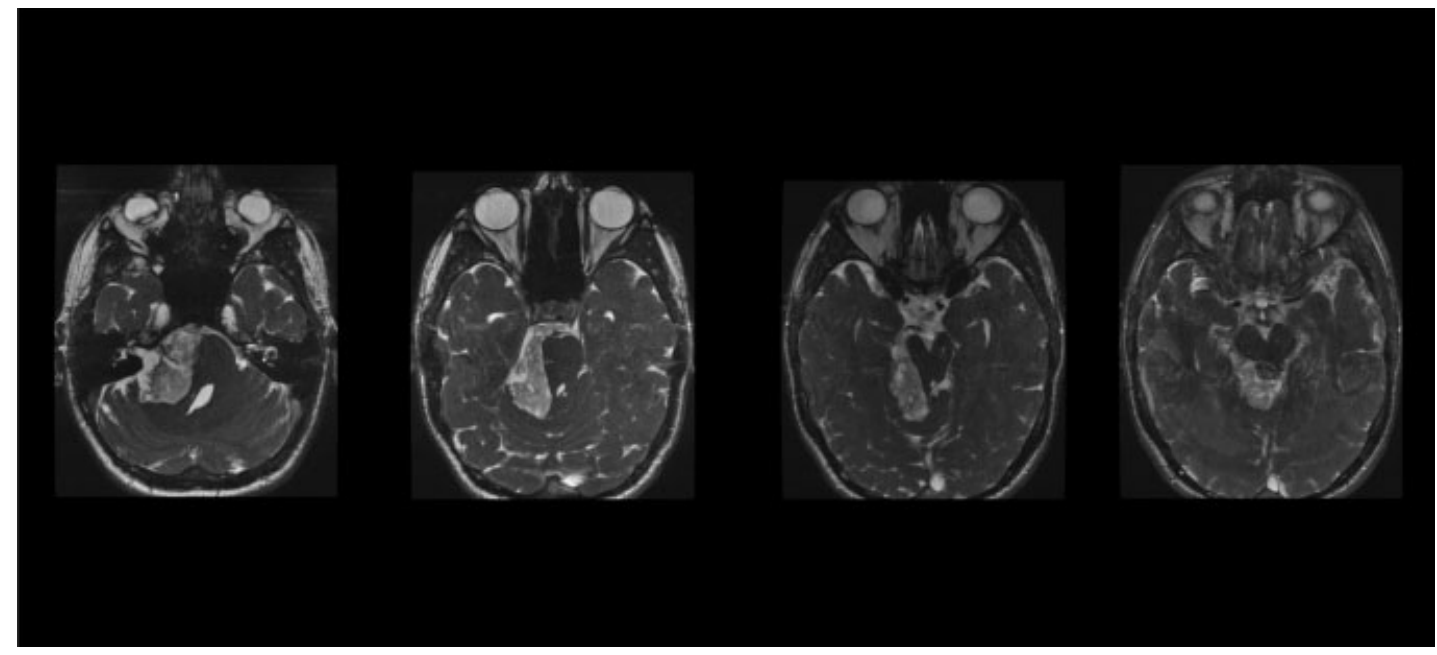

Fig. 1 MRI demonstrated an irregular lesion in the right cerebellopontine angle consistent with an epidermoid cyst. 